\section{Myocardial Biopsy in a History of Light-Chain Amyloidosis Patient With Serial Cardiac Magnetic Resonance Imaging Not Suggestive of Cardiac Involvement}

Hana Mizutani, MD; Shusuke Fukuoka, MD, PhD; Naoki Fujimoto, MD, PhD; Masaki Ishida, MD, PhD; Kakuya Kitagawa, MD, PhD;

Eiji Ishikawa, MD, PhD; Kaoru Dohi, MD, PhD;

Shunji Kawamura, MD, PhD;

Kyoko Imanaka-Yoshida, MD, PhD;

Hajime Sakuma, MD, PhD; Masaaki Ito, MD, PhD

A 77-year-old hypertensive woman with a history of amyloid light-chain (AL) amyloidosis was admitted due to heart failure (HF). She had been diagnosed with AL amyloidosis at the age of 58 and received chemotherapy. At the ages of 66 and 76, cardiovascular magnetic resonance imaging (CMRI) showed lateral non-specific subendomyocardial late gadolinium enhancement (LGE). Global native $\mathrm{T} 1$ and extracellular volume fraction (ECV) at the age of 76 were normal. 3-Tesla CMRI during this admission showed unchanged LGE (Figure A), but greater global native T1 $(1,393 \pm 209$ vs. $1,284 \pm 85 \mathrm{~ms}$; normal, $1,294 \pm 39 \mathrm{~ms}$ ) and ECV (39 \pm 9 vs. $26 \pm 4 \%$; normal, $26.1 \pm 1.4 \%$ ) than before (Figure B,C). Echocardiography showed eccentric left ventricular hypertrophy and diastolic dysfunction. To determine whether she had cardiac amyloidosis (CA), she received endomyocardial biopsy (EMB), which demonstrated amyloid deposition (Figure D-F). After 1 course of chemotherapy, the patient suddenly died. Necropsy showed amyloid deposition mainly on the small vessel wall.

Although global subendocardial LGE is a characteristic pattern of $\mathrm{CA}$, increases in native $\mathrm{T} 1$ and $\mathrm{ECV}$ may reflect amyloid deposition. ${ }^{1}$ The observed increases in native $\mathrm{T} 1$ and ECV might be related to the progression of amyloid deposition. The majority of deaths in AL amyloidosis are caused by CA. ${ }^{2}$ EMB should be performed for early CA diagnosis in AL amyloidosis with subtle HF symptoms and/or changes in MRI findings.

\section{Disclosures}

The authors declare no conflicts of interest.

\section{References}

1. Barison A, Aquaro GD, Pugliese NR, Cappelli F, Vergaro G, Mirizzi G, et al. Measurement of myocardial amyloid deposition in systemic amyloidsis: Insights from cardiovascular magnetic resonance imaging. J Intern Med 2015; 27: 605-614.

2. Falk RH. Diagnosis and management of the cardiac amyloidoses. Circulation 2005; 112: 2047-2060.

Received April 9, 2019; revised manuscript received May 13, 2019; accepted May 16, 2019; J-STAGE Advance Publication released online May 25, 2019 Time for primary review: 22 days

Department of Cardiology and Nephrology (H.M., S.F., N.F., E.I., K.D., M. Ito), Department of Radiology (M. Ishida, K.K., H.S.), Department of Pathology and Matrix Biology (K.I.-Y.), Mie University Graduate School of Medicine, Tsu; Department of Diagnostic Pathology, Tokyo Women's Medical University Medical Center East, Tokyo (S.K.), Japan

Mailing address: Naoki Fujimoto, MD, PhD, Department of Cardiology and Nephrology, Mie University Graduate School of Medicine, 2-174 Edobashi, Tsu 514-8507, Japan. E-mail: naokifujimo@ clin.medic.mie-u.ac.jp

ISSN-2434-0790 All rights are reserved to the Japanese Circulation Society. For permissions, please e-mail: cr@j-circ.or.jp

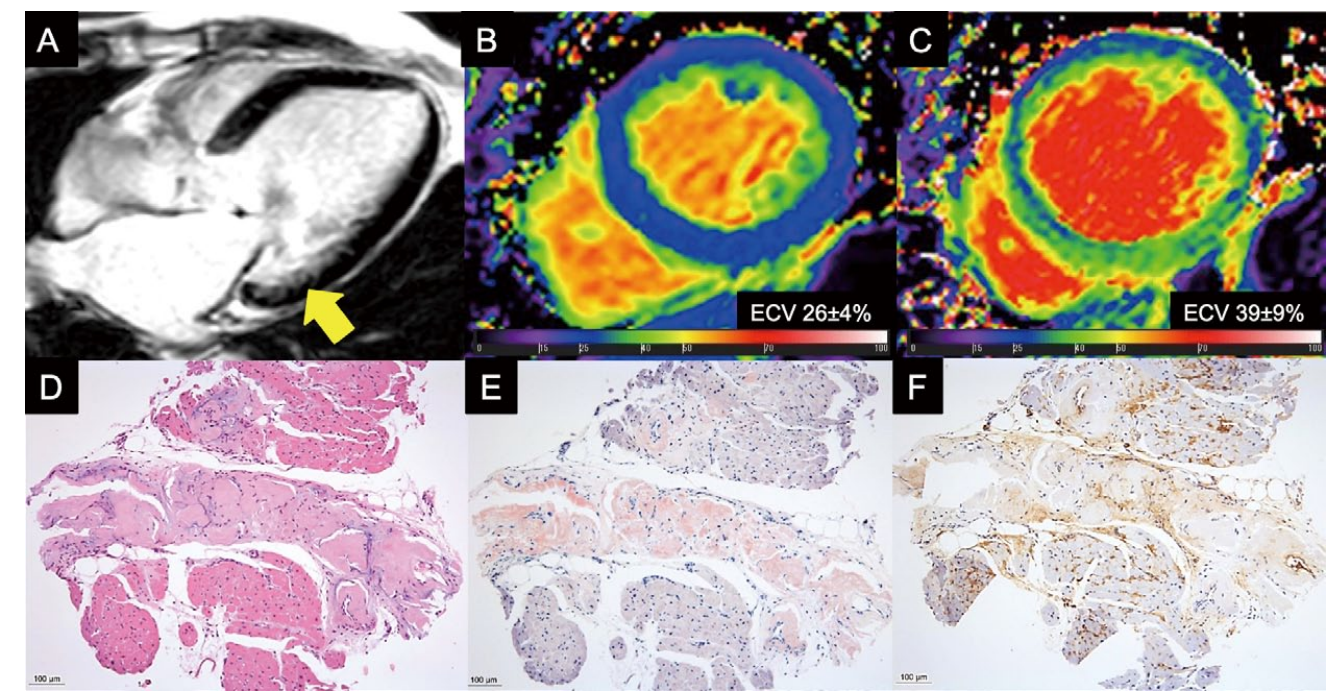

Figure. Cardiac magnetic resonance imaging showing (A) lateral late gadolinium enhancement (arrow) at the age of 77 years, and $(\mathbf{B}, \mathbf{C})$ global extracellular volume fraction at the ages of (B) 76 and (C) 77 . Histology on (D) hematoxylin-eosin stain, (E) Congo red stain, and $(\mathbf{F})$ immunostaining for lambda immunoglobulin light chain. 